of cells. Such a conclusion supports the hypothesis that influenza virus may be a co-factor in the development of bronchogenic carcinoma. Harris and Negroni, in a series of experiments, similarly exposed mice to influenza virus and also to influenza virus in combination with cigarette smoke. The results with influenza virus alone gave a low incidence of malignant lung tumours developing rather late in the life of the mice; preliminary results with the combination of influenza virus and cigarette smoke indicate that tumours appear earlier. Of particular interest in the lattor series of experiments is the appearance of a squamous cell carcinoma not unlike the lung tumours observed in human smoker's. The authors do not regard their findings as conclusive.

(3) Atmospheric pollutants. Tumours: (1) in the rat, with nickel carbonyl (Sunderman), and with asbestos (in the pleura, mesothelioma) (Wagner); (ii) in fowls, with asbestos (axillary air-sacs) (Peacock); (iii) in the hamster, with asbestos (in the pleura, mesothelioma) (Smith), with benzo(a)pyrene by means of dust particles (Saffiotti et al.), and with cigarette smoke (metaplastic and papillary processes in the trachea and bronchi) (Dontenwill and Wiebecke).

Experiments in mice have yielded the following results: (i) with denicotinized tobacco smoke condensate (decrease in the development of pulmonary tumours by $3,4,9,10$ dibenzpyrene) (Homburger and Treger); (ii) by the inhalation of tobacco smoke (after a year a single pulmonary tumour) (Harris and Negroni); (iii) with tobacco tar fractions (no increased incidence of pulmonary tumours) (Orr and Woodhouse). From the point of view of human pathology, Carnes and Moses reported that epithelial lesions have been studied, in autopsies, in relation to threo forms of atmospheric pollution: (a) smoking history; (b) residence, classified by size; $(c)$ occupation. Epitholial lesions of the trachea and bronchi proved to be more severe in those cases with a smoking history. According to Kreyberg, cigarette smoking, and to a lesser extent pipe smoking, may be considered to be particularly responsible for lung cancer.

(4) Chemicals. Tumours: (i) in the rat, with $N, N^{\prime}-2,7$ fluorenylenebisacetamide and related aromatic amines (Morris), 9,10-dimethyl-1-2-benzanthracene, 3,4-benzpyrene and 3-methylcholanthrene (Crocker and B. I. Nielsen), 20-methylcholanthrene and 3,4-benzyprene (Laskin et al.), $N$-methyl- $N$-nitrosourethane (Schoental); (ii) in tho mouse $N$-nitrosodiethylamine and $N$-nitrosodimethylamine (Takayama and Oota), 4-nitroquinoline-N-oxide (Kinosita), 3-metbylcholanthrene and 4-nitroquinoline- $N$-oxide, new-born and adult (Tsubura and Kimura), urethane (Tamnenbaum; Ribacehi and Giraldo; at high altitude, Mori-Chavez), 'Imferon' (Langvad), hydrazine (Biancifiori et al.) and its derivatives (Clayson et al.); (iii) in the hamster, with diethylnitrosamine (Dontenwill and Wiebecke); (iv) in the white Pekin duck, with methylcholanthrene (Rigdon).

In the rabbit, Griciute produced adenomatosis with dimethylbenzanthracene, and Moran showed that cortisone, administered after pulmonary lesions had been produced by chemicals, resulted in temporary hyperplasias of the epithelial type. In the pulmonary tumours of the rat by dimethylnitrosamine and diethylnitrosamine, changes occur in the protein-levels which seem to reflect systemic alterations in the whole organism (HochLigeti). The various degrees of alkylation of nucleic acids in the lungs and in other organs of the mouse, hamster and rat after treatment with carcinogenic nitroso compounds were studied in relation to the susceptibility of the organ to the carcinogen (Magee).

Briand and Kieler investigated the carcinogenic and co-carcinogenic effect of various oxygen tonsions on murine lung cells grown in vitro. Nitrosamines may be contained in cigarotte smoke even though they have not been demonstrated; it is possible, however, that they disappear rapidly (Boyland and Roe). Urethane may act as an accelerator only (Bentvelzen and Szalay) and, according to Boyland, by means of $N$-hydroxyurethane. It has been shown in the rat that even a serious lesion in the pulmonary tissue is not sufficient for the development of a cancerous growth in the presence of a weak carcinogen (Stanton and Blackwoll). Boeryd and Mellgren reported on the influence of heparin and epsilonamino-caproic acid on pulmonary metastases of malignant. tumours in mice.

\section{Summary}

In the final session of the conference, under the chairmanship of Lord Florey, Prof. Severi gave a summary of the contributions to the scientific programme. Little is known of the epidemiology, the biological behaviour and the pathology of spontaneous lung tumours in animals. The World Health Organization's programme in comparative oncology cortainly is welcome. Attempts to induce tumours in the respiratory system by means of physical, viral and chemical agents must bo developed extensively, so that research in the field of pulmonary earcinogenesis can be widened. On this point, Balò considered drugs capable of producing lung tumours in animals while Sprunt reported that, by irritation of the pulmonary epithelium with non-carcinogenic substances, lung tumours can be produced in the rabbit. The last mentioned is perhaps an important step for the understanding of pulmonary carcinogenesis. The results reported on experimental carcinogenesis by tobacco did not extend our knowledge beyond the known facts: that smoke condensate is a complete carcinogen, if a weak one, for the skin of the mouse and the rabbit, for the mouse cervix, for the subcutaneous tissue of the rat and also for the trachea of the dog. Nothing is known for sure of its carcinogenie action on the bronchial epithelium, perhaps because of the technical difficulties. A great deal is known about lung cancer in man, and a very great deal about so-called 'spontaneous' and induced lung cancer in animals, but the cause of lung cancer in man or of spontaneous lung cancer in animals remains obscure.

Prof. Severi agreed with Hockett that much systematic, methodical, step-by-step research with animal models must be done. So far as man is concerned, what is not understood cannot be prevented. For this reason there is little to expect from preventive medicine, but much to hope for from basic research.

The Proceedings of the conference will be published, as usual, by the Division of Cancer Research, P.O.B. 167, Perugia, Italy.
L. SEVERI

\title{
PLANNING A NEW MEDICAL SCHOOL
}

$I^{\mathrm{x}}$ N July 1964 the Minister of Health informed Parliament that a new medical school was to be established in the University of Nottingham, with an intake of 100 students a year, in conjunction with a new teaching hospital of 1,200 beds. For three years before this announcement, the University had been engaged in negotiations, during which much thought was given to the problems involved.
In October 1964 the University Council, at the request of the Senate, decided to set up a Medical School Advisory Committee to offer advice and recommendations to the University on medical education, teaching and research, on the best arrangements for the nature and lay-out of the buildings required, and on the University's administrative relations with other bodies concerned. The Com- 
mittee 's report has now been published*, and as the proposed new medical school is the first to be established in Britain since the Welsh National School of Medicine, set up in Cardiff in 1893, the report is of considerable interest.

The report begins with a brief review of medical education in the past and then discusses the purpose of a university medical school, which should, it considers, like the university itself, have two chief functions: the pursuit of knowledge and the education of the young - that of training for a profession, although a vocational objective, is added. It is accepted, as a fundamental tenet, that the new medical school will encourage research, particularly in the growing points of medical science, and also that toaching and research are complementary. The Committee adopts three guiding principles and attempts (1) to shape the pre-clinical part of the course to conform in pattern and objective with that of other science depart. ments in the University; (2) to integrate and co-ordinate so far as possible pre-clinical and clinical departments and studies; (3) to plan the government, staffing and services of the hospital, to meet the needs of both the University and the community.

The curriculum and buildings of the new medical school should be designed in such a way as to develop and strengthen the links between: (1) the medical school and the rest of the University; (2) the pre-elinical and clinical parts of the school; (3) the hospital and tho community it serves. The Committee suggests that the medical school and hospital should be known as the "University of Nottingham Medical Centre". Because teaching and research are so closely associated it is imperative that the new medical school should offer facilities for research in terms of time, space, staff, equipment and moriey which will attract only the best.

The total of 100 medical students per annum is accepted as the number at which the new school should aim, but the building should be flexible enough to enable this number to be increased. No dearth of good candidates is expected, but over-specialization at school has serious consequences for medicine. Boys and girls wishing to study medicine, who have passes in Advanced-level Examinations in both arts and sciences or arts subjects alone, should be encouraged; suitable arrangements should then be made to teach them the chemistry, physics and biology required for the study of medicine. Students should be selected for their intelligence (as revealed by Ordinary- and Advanced-level Examination passes) and for their personal qualities and capacity for citizenship, as shown by their school records and by interview. Every effort should be made to reduce the segregation from other students, inevitable to some extent in a medical student's studies, by sharing in common residence, meals, sports and social facilities. Every inducement should be given to students to incorporate themselves into the general life of the university. Certainly, the present science library should be extended to cater for medicine.

As regards the curriculum, the report suggests that this should be designed to eultivate a student whose curiosity is enhanced and not diminished, who is familiar with the broad field of medical science and who has

* University of Nottingham. Report of the Medical School Advisory Committes. Pp. 76. (Nottingham: The University, 1965.) 6s. acquired the habit of learning. He should also have assimilated the ethos of medicine. The curriculum should be planned with the view of avoiding the chief defects of contemporary medical education, such as overcrowding, lack of integration between subjects taught at the same and different times, and too many examinations. Accord. ingly, it is recommended that lectures should not be excessive in number and attendance should, so far as possible, be voluntary. The student should have sufficient free time to read and work on his own initiative, both in the library and in the laboratory or wards. Details of the curriculum should be planned by an inter-departmental committer of teachers, appointed by the Faculty of Modicine with an independent chairman. This committee should include junior staff, and should seek opinion from students, and keep the curriculum continuously under review. To synthesize the contributions of different disciplines, lectures on different aspects of a single problem should be delivered consecutively and followed by group discussions. Clinical demonstrations should bo given throughout the pre-clinical period so as to emphasize the unity of knowledge and alleged vocational aspects of the curriculum, but it should not be allowed to dominate the educational aspects. Medical examinations should be reduced to the minimum compatible with the regulations of the General Medical Couneil.

It is suggested that the curriculum should consist of : period of three years' training for the biological scientist, whose interest is centred on man, followed by two years of clinical training and two pre-registration years. For those students who have not studied science at school, the University should provide an introductory year of science. The first-degree course in medical biological sciences is visualized as forming the third limb of a tripod, of which the other two would be a school of general biological sciences, within the faculty of pure science, and a school of agricultural biological sciences within the faculty of agricultural sciences. The teaching hospital should provide for the needs of the community and of the University and its services, and include geriatrics, psychiatry and infectious diseases in a certain area. The size of the units may require modification to meet the teaching and research needs of the University. The teaching hospital and medical school should be designed and constructed as a unit, to permit as free as possible an interchange of people and a maximum flexibility. It is suggested that the governing body of the new teaching hospital should be constituted by the Regional Board and the University (as equal partners), and that it should be responsible for obtaining the necessary finance from the Ministry of Health and the University Grants Committee. It is also recommended that the Department of Community Health should contain a sub-department of general practice, the function of which would be to help in the organization of general practice in the area, and to encourage the provision of better working conditions for general practitioners and thus better service for patients. The medical school and the teaching hospital should be designed as an entity. The Committee would regard a start in temporary accom. modation as both extravagant and undesirable, as it may result in loss to the University of some of the best senior staff- on whom the future of the medical centre depends.

\section{NATURE CONSERVANCY IN BRITAIN}

I it paper, "Advances in British Nature Conservation", now preprinted from the Society's handbook for $1965^{*}$, Mr. E. M. Nicholson, director-general of the * Society for the Promotion of Nature Reserves. Advances in British
vature Comservation. Nature Conservation. (Preprint from the Soclety's Handbook for 1965.) By E. M. Nicholson. Pp. 16. (London: Society for the Promotion of
Nature Regerves, 1964.)
Conservancy, summarizes some of the recent changes in the concepts, practices and scale of conservation of natural areas in Great Britain in recent years.

Conservation has now ceased to be the affair of a local minority and has become a major nation-wide project. The vague idea that reserves are a good thing and 